\title{
EXCLUSIVE BREASTFEEDING, DIARRHEA, AND THEIR ASSOCIATION WITH MOTOR DEVELOPMENT IN CHILDREN IN 1000 DAYS FIRST LIFE
}

\author{
Dahliansyah'), Diffah Hanim²), Harsono Salimo3) \\ 1)Master Program of Nutrition Science, Universitas Sebelas Maret \\ 2)Department of Nutrition, Faculty of Medicine, Universitas Sebelas Maret \\ 3)Department of Pediatrics, Dr. Moewardi Hospital, Surakarta
}

\begin{abstract}
Background: The right nutrition during 1,00o day window has a profound impact on a child's ability to grow, learn, and thriveand eventually a lasting effect on a country's health and prosperity. Nutrition during pregnancy and the first two years of a child's life provides the essential building blocks for brain development, healthy growth, and a strong immune system. Diarrhea disease is the second leading cause of death in children under five years old. It is both preventable and treatable. Each year diarrhea kills around 525 ooo children under five worldwide. Exclusive breastfeeding reduces infant mortality due to common childhood illnesses such as diarrhea or pneumonia, and helps for a quicker recovery during illness. Breast milk promotes sensory and cognitive development, and protects the infant against infectious and chronic diseases. Little is known about the effect of exclusive breastfeeding and diarrhea on the neurodevelopment of children under five in Indonesia. This study aimed to estimate the effect of exclusive breastfeeding and diarrhea on the neurodevelopment of children under two years in Indonesia.
\end{abstract}

Subjects and Method: This was an analytic observational study with a crosssectional design. The study was conducted in Pontianak, West Kalimantan, in January 2018. A sample of 138 children under two years ( $\geq 6-24$ months) along with their mothers was selected for this study. The dependent variable was motor development. The independent variables were exclusive breastfeeding and diarrhea. Motor development was measured by development pre-screening questionnaire (KPSP). The other variables were measured by questionnaire and health record. The data were analyzed by logistic regression.

Results: The likelihood of normal motor development in children under two years increased with exclusive breastfeeding, and it was statistically significant $(\mathrm{OR}=2.17 ; 95 \% \mathrm{CI}=1.01$ to $4.65 ; \mathrm{p}=0.036)$. The likelihood of normal motor development decreased with the incidence of diarrhea $(\mathrm{OR}=0.79 ; 95 \% \mathrm{CI}=0.33$ to $1.09 ; \mathrm{p}=0.596$ ) but not statistically significant.

Conclusion: Exclusive breastfeeding is beneficial to increase the likelihood of normal motor development in children under two years.

Keywords: motor development, exclusive breastfeeding, diarrhea

\section{Correspondence:}

Dahliansyah, Master Program of Science Nutrition, Universitas Sebelas Maret, Jl. Ir. Sutami 36A, Surakarta 57126, Central Java.

Email: dahlian_syah_gz@yahoo.co.id. 